\title{
Evaluation of Developing Agricultural Recycling Economy in Hebei
}

\author{
Chen Wei ${ }^{1, a}$ and Lin $\mathrm{Nan}^{2, \mathrm{~b}}$ \\ ${ }^{12}$ School of Economics and Management, \\ Hebei University of Science and Technology \\ Shijiazhuang, 050018, China, \\ a1329982669@qq.com, b84409261@qq.com
}

Keywords: Recycling economy; Agricultural economy; Analytic hierarchy process; Analysis and evaluation; Agricultural development.

\begin{abstract}
On the basis of agricultural recycling economy's connotation, this paper constructs index system to comprehensively evaluate the development of agricultural recycling economy, which includes 4 classification indexes, namely, economic and social development, resource reduction and input, resource recycling and reutilization, and resource environment and security, altogether 16 operational indexes. Then, this paper assesses the development of agricultural recycling economy in Hebei from 2004 to 2013. The results show that the overall level of Hebei agricultural recycling economy increases gradually, which is mainly driven by the increase of agricultural output. Reduction of resource input is the major constraint factor; resource recycling level has been maintaining the same for years; agricultural resource environment and security are basically guaranteed.
\end{abstract}

\section{Introduction}

The overall objective of agriculture with recycling economy is to reduce the investment of resources and materials in the life cycle of agricultural products as well as outputs and emission of waste for the positive interaction between agricultural economy and ecological benefits. The development mode of recycled agricultural economy is the most fundamental and effective way to truly change the operation of economy, improve efficiency of resource utilization, reduce environmental pollution and protect ecological environment.

Agriculture plays a pivotal role in national economy, and as a major agricultural province, Hebei has the objective requirements for developing agricultural recycling economy. First of all, there is a huge pressure on Hebei's population and resources. Till the end of 2014, there were 73,837,500 people in Hebei, which is expected to increase to 76 million in 2020. How to solve the problem of food self-sufficiency to such a large amount of population is particularly important to ensure the national food security. Contradiction between people and land is very prominent in Hebei with extreme water scarcity. Drought and disasters affect an increasing huge area in recent years. Secondly, as the most important food, fruit and vegetable and livestock production base, Hebei has strong momentum of export-oriented agricultural economy. With the improvement of people's living standards and diet structure, there is growing demand for the quantity and quality of agricultural products, providing huge market space for the development of agricultural recycling economy. In addition, located at the special location of inner Beijing-Tianjin ring, Hebei is the ecological barrier and water conservation of both Beijing and Tianjin as its agro-ecological environment is not only related to its own development, but also has a significant impact on the ecological environment of both Beijing and Tianjin.

In order to realize sustainable development of Hebei's agriculture and accelerate the construction of recycling agriculture, scientific evaluation of the development of agricultural recycling economy has important practical significance to analyzing the advantages and disadvantages of developing agricultural recycling economy. Domestic scholars have made preliminary exploration into the development of agricultural recycling economy[1,2], the obvious common points of which are the 
established index system is territorial, and the evaluation results has obvious referential significance for guiding the development of regional agricultural recycling economy while not being universal. Therefore, corresponding evaluation should be made according to the actual development of each region in order to guide the development of each region more accordingly[3,4].

\section{Construction of metric system to measure the development of recycling economy and determination of weights}

Principles in constructing metric system to measure the development of agricultural recycling economy. Evaluation of agricultural recycling economic development is comprehensive with the index being able to fully, comprehensively and systematically reflect the material recycling and energy conversion of agricultural recycling economic system[5].

Targeted principle: the index system must address the essential connotation of recycling economy and truly reflect the development of agricultural economic system's recycling function. According to the "reduction", the output of resources, "recycling" and waste of "re-use" principle inputs into agricultural production systems, taking into account social, economic and ecological benefits of unity.

Feasible Principle: To ensure comparability index data, can be found and quantitative, make full use of available statistics to ensure statistical consistency, ease of analysis results of the application.

Level Principle: Any index of the development of agricultural recycling economy is internally related to other indexes. In order to construct index system to evaluate the development of regional agricultural recycling economy, different levels of agricultural recycling economy's development should be fully reflected within the overall target so as to choose operational indexes at different levels.

Leading Principle: There are complicated factors affecting the system of agricultural recycling economy and they have different degrees of impact on the system. Main contradiction must be grasped in choosing index and main factors affecting the system's material recycling and energy flow should be chosen so as to make the evaluation results more scientific.

Systematic Principle: Agricultural circular economy is to achieve high efficiency, reduction of the use of agricultural resources, effective security resources and the environment, to achieve the ultimate goal of economic development and social progress[6].

Constitution of Index System to Evaluate the Development of Agricultural Recycling Economy. Taking into account the complexity of content and a full range of agricultural circular economy, development of agricultural circular economy evaluation index system consists of 4 types of indicators and indexes of 16 operations (Table 1), in which the connotation of agricultural circular economy to set the class extension of operation index is a detailed description of the types of indicators[7].

Weight Determination of Agricultural Recycling Economic Development Indexes. Analytic hierarchy process (AHP) is used in this research to determine the weight of each index, and the results of calculating the weight of index at each level is shown in Table 1.

\section{Empirical Research of Evaluating the Development of Agricultural Recycling Economy in Hebei}

Acquisition of Original Data. Original data in this research are taken from 2004-2013 Hebei Economic Yearbook, Statistical Yearbook of Rural Hebei Province, Hebei Water Resource Bulletin as well as Hebei environment statistics and statistics of animal husbandry in Hebei Province[8].

Standardized Process of Original Data. In order to unify the index dimension and narrow the numerical differences between indexes, reference value's standardization method is used, that is, take 2004 as the reference year and ratio of corresponding operational index of other years to reference value as the normalized value. Standardized method of the reference value is targeted at two types of indexes, one is the negative index that the smaller the original value, the more beneficial to recycling 
economy, such as ten thousand yuan agricultural production, water consumption and agricultural energy consumption index, etc. Another is positive index that the larger the original value, the more beneficial to recycling economy, such as farmers' per capital net income and crop utilization rate, etc.

The specific calculation method is as followed:

Negative index: $X$ i $j^{\prime}=S i j / X$ i $j$ (1) Positive index: $X$ i j ${ }^{\prime}=X i j / S$ i $j$ (2)

In the formula, $\mathrm{Xij}^{\prime}$ is the $\mathrm{j}$ operation index value of $\mathrm{i}$ category after the standardization process, $\mathrm{Xij}$ refers to the original value of $\mathrm{j}$ operation index of $\mathrm{i}$ category, and $\mathrm{Sij}$ refers to the original value of $j$ operation index of i category in the reference year.

Table 1 Index and Weight Value of Agricultural Recycling Economic Development

\begin{tabular}{|c|c|c|c|}
\hline Target Level (A) & Control Level（B） & Index Level (C) & Weight \\
\hline \multirow{16}{*}{$\begin{array}{l}\text { Index to Evaluate Hebei } \\
\text { Agricultural Recycling } \\
\text { Economy (A) }\end{array}$} & \multirow{6}{*}{$\begin{array}{l}\text { Economic and Social } \\
\text { Development (B1) }\end{array}$} & $\begin{array}{l}\text { C11 Agricultural Production of Per Unit Area } \\
\text { (Yuan/hm2) }\end{array}$ & 0.11 \\
\hline & & $\begin{array}{l}\text { C12 Farmer's Per Capita Annual Net Income } \\
\text { (Yuan/people·year) }\end{array}$ & 0.11 \\
\hline & & C13 Per Capita Food Production $\left(\mathrm{kg} / \mathrm{hm}^{2}\right)$ & 0.11 \\
\hline & & C14 Grain Yield Per Unit Area $\left(\mathrm{kg} / \mathrm{hm}^{2}\right)$ & 0.11 \\
\hline & & $\begin{array}{l}\text { C15 Commodity Rate of farming, forestry, } \\
\text { animal husbandry and fishery }(\%)\end{array}$ & 0.05 \\
\hline & & $\begin{array}{l}\text { C16 Total Power of Agricultural Machinery } \\
\left(10^{4} \mathrm{kw}\right)\end{array}$ & 0.03 \\
\hline & \multirow{4}{*}{$\begin{array}{l}\text { Reduced Input of } \\
\text { Resources (B2) }\end{array}$} & C21 Intensity of Fertilizer C21 (kg/hm²) & 0.03 \\
\hline & & $\begin{array}{l}\text { C22 Agricultural Energy } \\
\text { Coefficient }\left(10^{4} / 10^{8} \text { Yuan }\right)\end{array}$ & 0.06 \\
\hline & & C23 Utilization of Fertilizer $\left(\mathrm{kg} / \mathrm{hm}^{2}\right)$ & 0.01 \\
\hline & & C24 Utilization of Plastic Sheeting $\left(\mathrm{kg} / \mathrm{hm}^{2}\right)$ & 0.06 \\
\hline & \multirow[t]{2}{*}{$\begin{array}{l}\text { Resource Recycling \& } \\
\text { Reutilization (B3) }\end{array}$} & $\begin{array}{l}\text { C31 Fertilizer Effective } \text { Utilization } \\
\text { Coefficient (Yuan } / \mathrm{kg} \text { ) }\end{array}$ & 0.08 \\
\hline & & C32 Multiple Cropping Index (\%) & 0.08 \\
\hline & \multirow{4}{*}{$\begin{array}{l}\text { Resource Environment \& } \\
\text { Security (B4) }\end{array}$} & C41 Forest Coverage Rate (\%) & 0.07 \\
\hline & & C42 Effective Irrigation Coefficient & 0.02 \\
\hline & & C43 Per Capita Arable Land ( $\mathrm{hm}^{2} /$ people) & 0.01 \\
\hline & & $\begin{array}{l}\text { C44 Per Capita Water Resource Amount } \\
\left(\mathrm{m}^{3} / \text { people }\right)\end{array}$ & 0.06 \\
\hline
\end{tabular}

Construction of Evaluation Model. This research uses additive model to measure the development level of agricultural recycling economy, that is:

$$
S=\sum_{i, j=1}^{n, m} C_{i j} W_{i j}
$$$$
(i=1, \ldots, m ; j=1, \ldots, n)
$$

In the formula, $\mathrm{Cij}$ is the standardized value of each single index, Wij is the corresponding weight of each index and $\mathrm{S}$ is the comprehensive score from evaluating the development of agricultural recycling economy.

Analysis of Evaluation Results. Analysis of Comprehensive Development Level of Hebei Agricultural Recycling Economy 


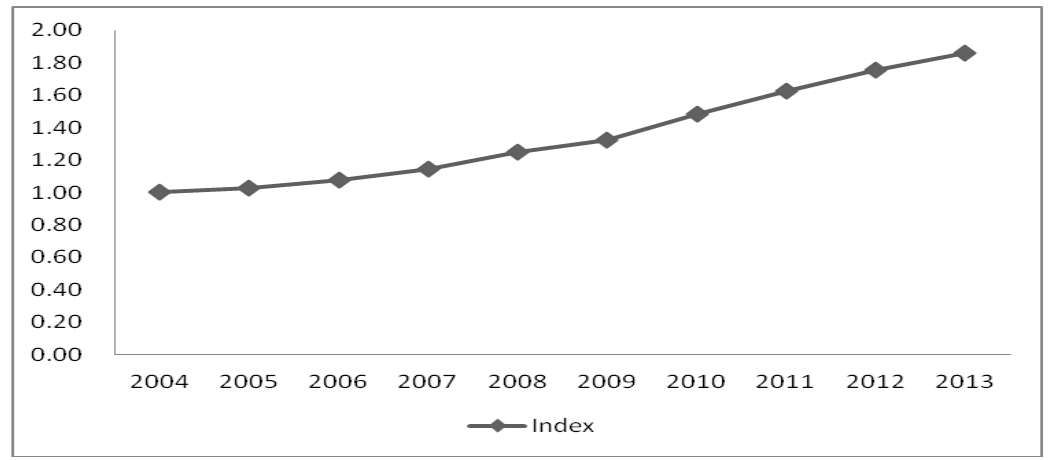

Fig. 1 Comprehensive Evaluation Results of 2004-2013 Agricultural Recycling Economy in Hebei

Process and calculate data collected by using the above evaluation method to obtain the results of comprehensive evaluation of Hebei agricultural recycling economic development (as shown in Fig. 1). It can be seen from Fig. 1 that in general, in 2004-2013, the development level of Hebei agricultural recycling economy gradually improves, and the comprehensive evaluation index of 2013 recycling economy is 1.86 times of that in 2004. during 2004-2006, comprehensive index of recycling economy is between [1,1.08], comprehensive evaluation index rate of change is slow, the average annual rate of 3.9 per cent rise for the infancy; period from 2007 to 2009, the circular economy index living between [1.15,1.32], with an average annual growth rate of $7.1 \%$, for the acceleration phase; 2010 economic composite Index to 2013 living between $[1.48,1.86]$, with an average annual growth rate of $7.9 \%$, in a relatively stable stage.

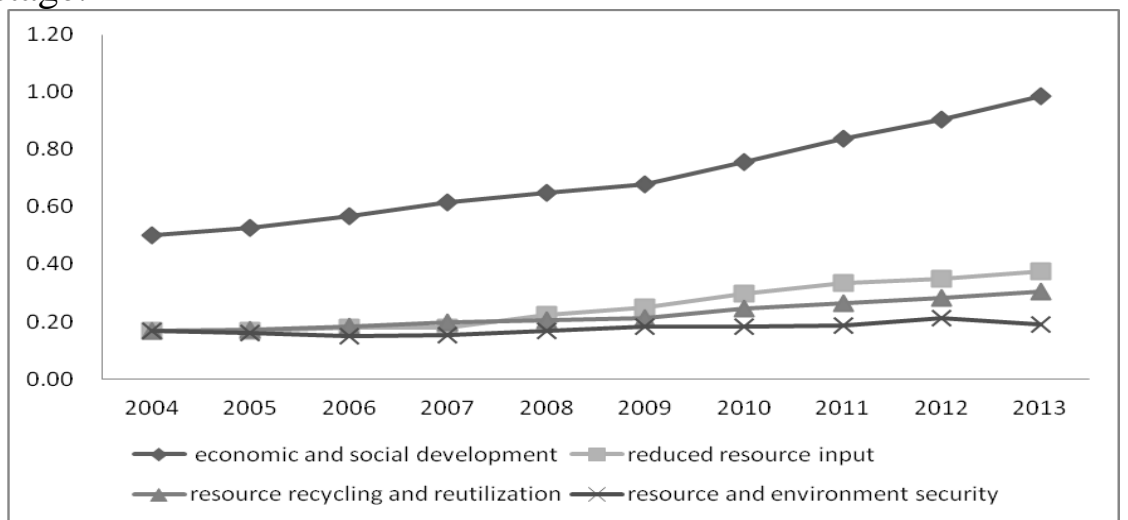

Fig. 2 Evaluation Results of 2004-2013 Hebei Agricultural Recycling Economic Development Indexes

Analysis of Hebei Agricultural Recycling Economic Development Indexes:

Economic and Social Development Index: it can be seen from the comparison of Fig. 1 and Fig. 2 that changes of economic and social development indexes are simultaneous to comprehensive evaluation indexes, and during 2004-2013, annual increase rate of economic and social development index is $7.9 \%$, and that of comprehensive evaluation index is $7.1 \%$, indicating that this kind of indexes have strong effect to pull the overall development of agricultural recycling economy. Its main contributions are farmers' per capital net income, grain yield per unit of area and commodity rate of agriculture, forestry, animal husbandry and fishery. This is mainly due to adjustment of Hebei planting structure and effective implementation of policies and measures to accelerate the development of animal husbandry.

Reduced resource input index: From 2004 to 2004, resource reduction in the level showed a trend of increase, but growth is not significant. During the use of the strength of fertilizer, pesticides, agricultural films level is the main limiting factor. Such as the 2004 fertilizer intensity of $333.37 \mathrm{~kg} /$ $\mathrm{hm} 2$, increased to $378.37 \mathrm{~kg} / \mathrm{hm} 2$ in $2013 ; 2004$ pesticide use level of $12.61 \mathrm{~kg} / \mathrm{hm} 2$, rose to $13.73 \mathrm{in}$ 2013. The index showed a trend of increase is mainly attributed to the government has published a series of measures of saving energy and reducing consumption makes agricultural energy dissipation 
coefficient by $0.38103 \mathrm{t} / 108$ yuan in 2004 to $0.08103 \mathrm{t} / 108$ yuan in 2013, but this time, the chemical fertilizers, pesticides, agricultural films use level has not been effectively reduced.

Resource recycling and reutilization index: The indicators from the 2004-2012 showed a slowly increasing trend, possible causes are: multiple cropping conditions from 2004-2013, Hebei province, has been stabilized, an increase is very small; changes in effective use of chemical fertilizers is positive and significant, but in consideration of the weight settings because of their importance, equivalent to the weight of the two, therefore, resources recycling indicators change is not obvious[9].

Resource and environment security index: The growth rate of the index from 2004-2012 is extremely slow the same and 2002-2003 show a downward trend, the main limiting factor is the decline in per capita arable land resources, the reason is consuming large amounts of urban construction land and country returning farmland to forest and grassland project was launched. Among them, as environmental awareness increased and the implementation of policies for returning farmland to forest and grassland, and forest cover per capita water resources in growth, the coefficient of effective irrigation essentially flat over the years, however, countries should also further improve the efficiency of agricultural water use for irrigation.

To sum up, there is a trend of gradually increase annually in the overall agricultural recycling economy in Hebei province, the main pulling factor is the increase of agricultural output, but reduced resource input is the biggest restriction factor. Reutilization of agricultural resources progresses slowly for years, and resource and environment security has been basically guaranteed. It is expected that with the implementation of "the Twelfth 'Five-Year Plan' of Hebei Ecological Environment Protection" and national indemnifying measure of ecologic environment in Hebei, agricultural recycling economy will be significantly improved during the twelfth "five -year" plan[10].

\section{References}

[1] Guo Shutian. Recycling Agriculture has Broad Prospect for Development - Speech Delivered at Agricultural Recycling Economy Information Exchange [J] Journal of China Eco-Agriculture, 2009, (5)

[2] Jiang Fazhu, Yang Chunbo, Hu Cuixia. Evaluation of Developing Agricultural Recycling Economy in Heilongjiang [J]. Chinese Agricultural Bulletin, 2007, 23(9):645-648

[3] Feng Zhijun. Legislative Process should be speeded up to Develop Recycling Economy [J]. China's Investment in Science and Technology, 2006 (3)

[4] Huang Gaobao, Yu Aizhong, Chai Qiang. Application of Main Recycling Agricultural Mode in Irrigation Land, Northwest China and its Need to Develop Technologies [A]. Research of Process of Recycling Agriculture in China [C]. Beijing: China Agricultural University Press, 2010,8:28-34

[5] Zhang Xuehui, Zhao Kai, Hu Yuan, Zheng Qiaofeng. Review and Evaluation of Recycling Agriculture in China [J]. World Agriculture, 2008(9):8-11

[6] He Juan. Thoughts and Suggestions on Developing Agricultural recycling economy in China [J]. China's New Technologies and New Products, 2013(2): 12-14

[7] Wang Feng. Exploration New Ways to Develop Agricultural recycling economy [J]. Agriculture in Henan, 2013(5):23-24

[8] Yang Hui. Problems in Developing Grassroots Agricultural recycling economy and Measures [J]. Agricultural Information in China, 2013(5): 30-31

[9] Chi Qishui, etc. Evaluation of Recycling Economy's Efficiency in Beijing Based on DEA Method [J]. Ecological Economy, 2010 ():74-78

[10] Huang Xianjin. Industry mode and policy system[M].Nanjing: Nanjing university press,2004 